\title{
Numerical Simulation for the Effect of Joint Inclination to the Stability of Stratified Rock Slope
}

\author{
Qihong $\mathrm{Wu}$, \\ School of Urban and Rural Construction \\ Chengdu University \\ Chengdu, China \\ e-mail:wqh1016@126.com
}

\author{
Zhiyong Kou, Shiming Wan \\ School of Urban and Rural Construction \\ Chengdu University \\ Chengdu, China
}

\begin{abstract}
Slope excavations are often constructed in stratified host rock masses in practice. In order to describe the effect of the inclination of layer of rock mass to the factor of safety of slope. a rock slope in one road is chosen as the engineering project. In the present paper, the stability mechanism of slope is analyzed. Numerical models for the slope are founded, the application method of shear strength reduction technique is discussed, and the convergence of numerical computations criterion is chosen as the failure criterion for slope. At last, according to the numerical calculation results, the influential factors to the stability of stratified rock slope are analyzed, to give guidance for the real practice.
\end{abstract}

Keywords-Stratified rock, slope, factor of safety, joint inclination

\section{INTRODUCTION}

Slope excavations are often constructed in stratified (layered) host rock masses in practice [1]. The stratification in a rock mass is generally characterized by its planar geometry and persistence, such that it can be assumed to be continuous over plan areas much greater than that of the excavation[2]. It is obvious that the mechanical properties of the joints dictate both the deformation and strength characteristics of the stratified rock mass[3]. Thus, it is imperative that the influence of the joints be incorporated in any type of load-deformation analysis of slope excavations in layered rock masses.

In the present paper, a rock slope in one road is chosen as the engineering project. Firstly, the stability mechanism of slope is analyzed. Secondly, numerical models for the slope are founded by fast lagrangian analysis of continua three dimensions (FLAC3D), the application method of shear strength reduction technique[4,5] in Ubiquitous-Joint model is discussed, and the convergence of numerical computations criterion is chosen as the failure criterion for slope. At last, according to the numerical calculation results, the influential factors to the stability of stratified rock slope are analyzed, to give guidance for the real practice.

\section{NUMERICAL MODEL}

The numerical solution for predicting the strength of stratified rock mass is done by the ubiquitous-joint model in FLAC3D. This model accounts for the presence of an orientation of weakness (weak plane) in a FLAC3D MohrCoulomb model. The criterion for failure on the plane, whose orientation is given, consists of a composite MohrCoulomb envelope with tension cutoff. The position of a stress point on the latter envelope is controlled by a nonassociated flow rule for shear failure, and an associated rule for tension failure. In this numerical model, general failure is first detected and relevant plastic corrections are applied. The new stresses are then analyzed for failure on the weak plane and updated accordingly.

The weak-plane failure criterion used in this model is a composite Mohr-Coulomb criterion with tension cutoff expressed in terms of $\left(\sigma_{3^{\prime} 3^{\prime}}, \tau\right)$, as illustrated in Figure.1. The failure envelope $\mathrm{f}\left(\sigma_{3^{\prime} 3^{\prime}}, \tau\right)=0$ is defined from point $\mathrm{A}$ to $\mathrm{B}$ by the Mohr-Coulomb failure criterion $\mathrm{f} \mathrm{s}=0$, with

$$
f^{s}=\tau+\sigma_{3^{\prime} 3^{\prime}} \tan \phi_{j}-c_{j}=0
$$

and from $\mathrm{B}$ to $\mathrm{C}$ by a tension failure criterion of the form $\mathrm{ft}$ $=0$, with

$$
f^{t}=\sigma_{3^{\prime} 3^{\prime}}-\sigma_{j}^{t}=0
$$

where $\phi_{j}, c_{j}$ and $\sigma_{j}^{t}$ are the friction, cohesion and tensile strength of the weak plane, respectively. Note that, for a weak plane with nonzero friction angle, the maximum value of the tensile strength is given by,

$$
\sigma_{j \max }^{t}=\frac{c_{j}}{\tan \phi_{j}}
$$

The potential function is composed of two functions, $g_{s}$ and $g_{t}$, used to define shear and tensile plastic flow, respectively. The function $g_{s}$ corresponds to a nonassociated law and has the form,

$$
g_{s}=\tau+\sigma_{3^{\prime} 3^{\prime}} \tan \psi_{j}
$$

where $\psi_{j}$ is the weak-plane dilation angle. The function $g_{t}$ corresponds to an associated flow rule and is written,

$$
g_{t}=\sigma_{3^{\prime} 3^{\prime}}
$$


The flow rule is given a unique definition by application of the following technique. A function $h\left(\sigma_{3^{\prime} 3^{\prime}}, \tau\right)=0$, which is represented by the diagonal between the representation of $\mathrm{f} \mathrm{s}=0$ and $\mathrm{f} \mathrm{t}=0$ in the $\left(\sigma_{3^{\prime} 3^{\prime}}, \tau\right)$ plane (see Figure.2), is defined. The function is selected with its positive and negative domains, as indicated on the figure, and has the form,

$$
h=\tau-\tau_{j}^{P}-a_{j}^{P}\left(\sigma_{3^{\prime} 3^{\prime}}-\sigma_{j}^{t}\right)
$$

where $\tau_{j}^{P}$ and $a_{j}^{P}$ are two constants defined as

$$
\begin{gathered}
\tau_{j}^{P}=c_{j}-\tan \phi_{j} \sigma_{j}^{t} \\
a_{j}^{P}=\sqrt{1+\tan ^{2} \phi_{j}}-\tan \phi_{j}
\end{gathered}
$$

An elastic guess violating the composite yield function is represented by a point in the $\left(\sigma_{3^{\prime} 3^{\prime}}, \tau\right)$ plane located either in domain 1 or 2 , corresponding to positive or negative domains of $h=0$, respectively (see Figure.2). If in domain 1, shear failure is declared, and the stress point is placed on the curve $\mathrm{fs}=0$ using a flow rule derived using the potential function gs. If in domain 2, tensile failure takes place, and the stress point conforms to $\mathrm{ft}=0$ using a flow rule derived using gt.

The stress corrections for shear failure may thus be expressed as follows

$$
\begin{aligned}
& \Delta \sigma_{1^{\prime} 1^{\prime}}=-\lambda^{s} \alpha_{2} \tan \psi_{j} \\
& \Delta \sigma_{2^{\prime} 2^{\prime}}=-\lambda^{s} \alpha_{2} \tan \psi_{j} \\
& \Delta \sigma_{3^{\prime} 3^{\prime}}=-\lambda^{s} \alpha_{1} \tan \psi_{j} \\
& \Delta \sigma_{1^{\prime} 3^{\prime}}=\sigma_{1^{\prime} 3^{\prime}}^{0} \frac{\tau^{N}-\tau^{0}}{\tau^{0}} \\
& \Delta \sigma_{2^{\prime} 3^{\prime}}=\sigma_{2^{\prime} 3^{\prime}}^{0} \frac{\tau^{N}-\tau^{0}}{\tau^{0}}
\end{aligned}
$$

where the superscript 0 indicates the initial stress during calculation procedure; $\mathrm{N}$ indicates the update stress; the subscripts of stress indicate the direction, 1'1' is the direction of bedding plane inclination, 2'2' is the horizontal direction which perpendicular to 1 ' 1 ', 3 '' 3 ' is the normal direction of bedding plane; $\lambda^{s}=f^{s}\left(\sigma_{3^{\prime} 3^{\prime}}^{0}, \tau^{0}\right) /\left(2 G+\alpha_{1} \tan \psi_{j} \tan \phi_{j}\right), \quad \alpha_{1}$ and $\alpha_{2}$ is the shear modulus and bulk modulus of material, respectively, $\alpha_{1}=K+4 G / 3, \alpha_{2}=K-2 G / 3$ 。

$$
\text { When taking into consideration of }
$$
$\sigma_{i}^{N}=\sigma_{i}^{I}-\lambda S_{i}\left(\partial g / \partial \sigma_{n}\right)$ and $f=f^{t}$, the stress corrections for tensile failure may thus be expressed as follows

$$
\begin{aligned}
& \Delta \sigma_{1^{\prime} 1^{\prime}}=-\left(\sigma_{3^{\prime} 3^{\prime}}^{0}-\sigma_{j}^{t}\right) \frac{\alpha_{2}}{\alpha_{1}} \\
& \Delta \sigma_{2^{\prime} 2^{\prime}}=-\left(\sigma_{3^{\prime} 3^{\prime}}^{0}-\sigma_{j}^{t}\right) \frac{\alpha_{2}}{\alpha_{1}} \\
& \Delta \sigma_{3^{\prime} 3^{\prime}}=\sigma_{j}^{t}-\sigma_{3^{\prime} 3^{\prime}}^{0}
\end{aligned}
$$

where $c_{j}, \phi_{j}$ and $\sigma_{j}^{t}$ are the cohesion, friction angle, and tensile strength of bedding plane, respectively.

\section{CALCULATION}

The slope is $60 \mathrm{~m}$ height, with $50^{\circ}$ of slope angle, the inclination of joint plane is $0^{\circ} \sim 90^{\circ}$. The whole model consists of 556 elements, and 1218 grids. The model is fixed at the bottom boundary, and normal fixity at both side. The calculation model is shown in Figure.3. The UbiquitousJoint criterion is chosen to describe the soil, the parameters for the rock are shown in Table.1.

The inclination of joint has great impact on the factor of safety of slope, shown in Figure.4. If the joint inclination is large, it has little impact on the slope stability. If the joint inclination $\beta$ is $50^{\circ}$, the factor of safety is the smallest. The factor of safety $F$ shows the trend of first decrease then increase. If the joint inclination locates in the range of $\left[20^{\circ} \sim 30^{\circ}\right],\left[60^{\circ} \sim 70^{\circ}\right]$, the variation gradient of the safety factor is the largest, showing $\beta$ has great impact on $F$. If $\beta>80^{\circ}$, the safety factor decreases gradually.

\section{CONCLUSIONS}

The application method of shear strength reduction technique in Ubiquitous-Joint model is discussed, which shows that the parameters of rock mass and weakness plane are reduced at the same time, and the convergence of numerical computations criterion is chosen as the failure criterion for slope. At last, according to the numerical calculation results, the influential factors to the stability of stratified rock slope are analyzed, which show that the total safety factor $\mathrm{F}$ of slope first decreases then increases with the increase of joint dip angle $\beta$, the outline of curve for the relationship between $F$ and of $\beta$ is like shoulder which is higher on both side, and lower at the middle place.

\section{REFERENCES}

[1] LIN H, CAO P, LI J.T. Macroscopic effects of rock slope before and after grouting in joint plane[C]. The 10th International Symposium on Landslides and Engineered Slopes, Xi' an, 2008, PP: 815-820.

[2] TIEN Y.M, KUO M.C. A failure criterion for transversely isotropic rocks[J], Int J Rock Mech Min Sci, 2001, PP:399-412. 
[3] LIU K.D, ZHANG Y.J. Influence facors on shear failure orientation of layered rocks [J], Chinese Journal of Rock Mechanics and Engineering, 2002, PP:335-339.

[4] LIN H, CAO P, GONG F.Q. The directly searching method for potential slip surface and its influential factors based on the critical state of slope [J]. Journal of Central South University, 2009, PP:131135 .

[5] ZOU D.H, CUI Y. Effects of frequency and grouted length on the behavior of guided ultrasonic waves in rock bolts [J], International Journal of Rock Mechanics and Mining Sciences, 2007, PP:813-819.

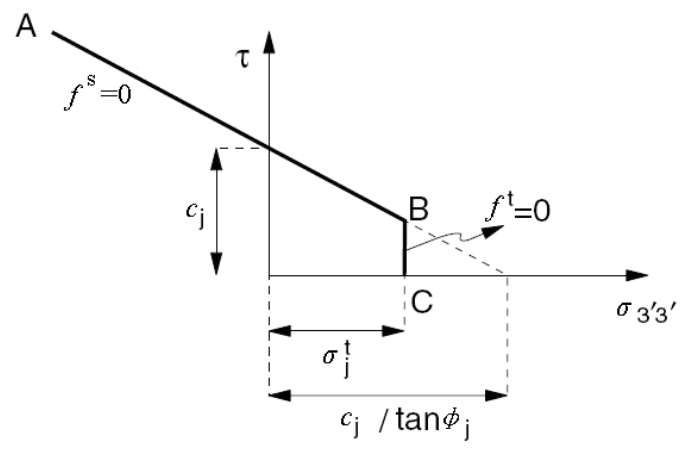

Figure 1. Failure criterion of stratification

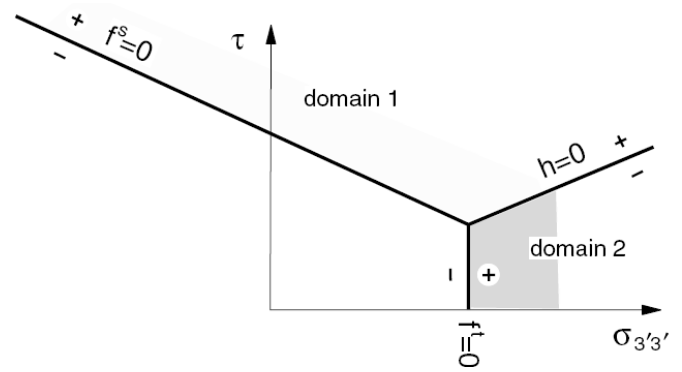

Figure 2. Ubiquitous-joint model — domains used in the definition of the weak-plane flow rule

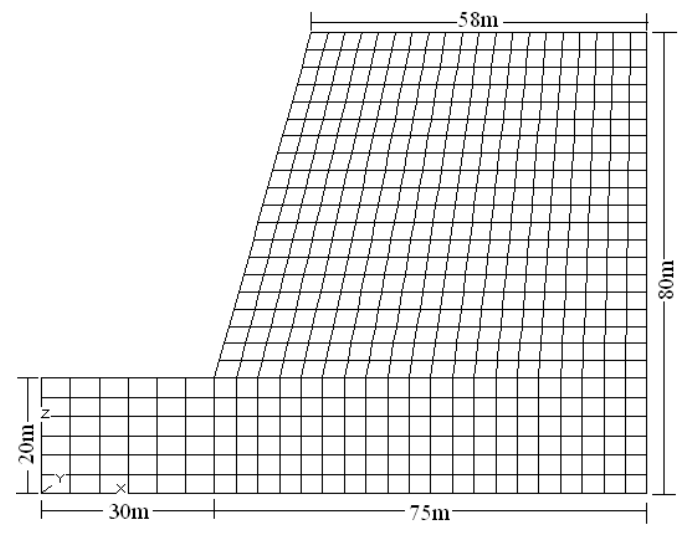

Figure 3. Calculation model 


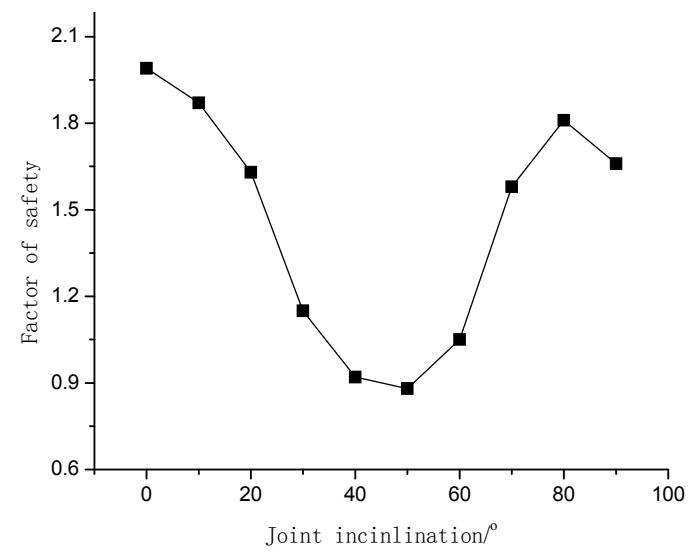

Figure 4. Relationship between factor of safety of slope and joint inclination

TABLEI. ROCK PARAMETERS

\begin{tabular}{|c|c|c|c|c|c|c|}
\hline $\begin{array}{l}\text { Rock } \\
\text { type }\end{array}$ & $\begin{array}{c}\text { Elastic } \\
\text { modulus } \\
\text { E(GPa) }\end{array}$ & $\begin{array}{c}\text { Poission's } \\
\text { ratio } \\
\mu\end{array}$ & $\begin{array}{c}\text { Unit } \\
\text { weight } \\
\left(\mathbf{k N} / \mathbf{m}^{3}\right)\end{array}$ & $\begin{array}{c}\text { Cohesion } \\
\text { c(kPa) }\end{array}$ & $\begin{array}{c}\text { Friction } \\
\text { angle } \\
\phi\left(^{\circ}\right)\end{array}$ & $\begin{array}{c}\text { Tensile } \\
\text { strength } \\
\text { (kPa) }\end{array}$ \\
\hline $\begin{array}{l}\text { Rock } \\
\text { mass }\end{array}$ & 5.0 & 0.25 & 25.0 & 500 & 30.0 & 100 \\
\hline Joint & & & & 100 & 25 & 10 \\
\hline
\end{tabular}

